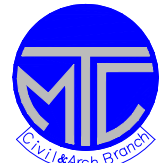

ICCAE
Military Technical College

Kobry Elkobbah,

Cairo, Egypt $7^{\text {th }}$ International Conference

Civil \& Architecture

Engineering

\title{
DISPLACEMENT-BASED SEISMIC DESIGN OF SKEW RC BRIDGE PIERS
}

\author{
AYMAN HUSSEIN HOSNY KHALIL', SHEHAB MOURAD', \\ MOHAMED NOUR FAYED ${ }^{\prime \prime}$, AND MOHAMED ABDEL AZIZ
}

\begin{abstract}
Current bridge codes and standards apply ordinary bridge seismic design procedures to skew bridges neglecting the torsional and bilateral effects during the seismic excitations. As a result, there is a need to investigate the seismic behaviour of skew bridge piers. This paper highlights the important features of displacement based seismic design. Then, it provides the details and the results of a theoretical parametric study to assess the seismic performance of skew bridge's piers. The theoretical study parameters are the skew angle, the pier height to thickness ratio, and the vertical reinforcement ratio. A commercial nonlinear finite element software package, Strand 7, was used in the analysis. A force controlled pushover analysis with triangular load pattern was applied to push pier models. The performance relationships of secant stiffness, length of the formed plastic hinge, and displacement ductility to pier geometry, and vertical reinforcement ratio were developed for skew bridge's piers. Results show that displacement ductility for skewed piers is very sensitive to the variation of the skew angle at low skew angles especially for low vertical reinforcement ratio. Further, the displacement ductility is reduced as the amount of vertical reinforcement increased with the confining reinforcement ratio being constant. It was also shown that the effect of skew angle becomes less
\end{abstract}

\footnotetext{
'Associate Professor, Department of Structural Engineering, Ain Shams University.

Associate Professor, College of Engineering, King Saud University, Saudi Arabia.

Professor, Department of Structural Engineering, Ain Shams University.

'Structural Engineer, Dar Al-Handasah Consultants (Shair and Parteners), Giza, Egypt.
} 
significant for small skew angles and for short piers. Finally, the secant stiffness changed significantly with skew angle variation for short piers.

Keywords: Skew bridge's piers; displacement based seismic design; displacement ductility; secant stiffness; plastic Hinge.

\section{INTRODUCTION}

The latest edition of the American Association of State Highway and Transportation Officials, AASHTO-LRFD [1] requires that all bridges and their foundations shall have a clearly identifiable Earthquake Resisting System (ERS) selected to achieve the Life Safety Criteria with the objective to consider a seismic hazard corresponding to a $7 \%$ probability of exceedance in 75 years. The specifications warrant higher levels of performance, such as the operational objective, which might be established and authorized by of the bridge owner. Life safety for the design event shall be taken to imply that the bridge has a low probability of collapse, however, may suffer significant damage and significant disruption to service is possible. Partial or complete replacement may be required. The ERS shall provide a reliable and uninterrupted load path for transmitting seismically induced forces into the surrounding soil and sufficient means of energy dissipation and/or restraint to, reliably, control seismically induced displacements. All structural and foundation elements of the bridge shall be capable of achieving anticipated displacements consistent with the requirements of the chosen design strategy of seismic resistance and other structural requirements. Seismic performance is typically better in systems with regular configurations and evenly distributed stiffness and strength. Thus, typical geometric configuration constraints, such as skew, unequal pier heights, and sharp curves, may conflict with seismic design goals. Codes require that design to be based on one of the following three global seismic design strategies: (1) ductile substructure with essentially elastic superstructure, (2) essentially elastic substructure with a ductile superstructure, and (3) elastic superstructure and substructure with a fusing mechanism between the two. In the first strategy, conventional plastic hinging in columns, walls, and abutments are utilized to limit inertial forces by full mobilization of passive soil resistance. Also included are foundations that may limit inertial forces by in-ground hinging, such as pile bents and integral abutments on piles. The second strategy applies only to steel superstructures and ductility is achieved by ductile elements in the pier cross frames. In the third strategy, seismically isolated structures and structures where supplemental energy dissipation devices, such as dampers, are used to control inertial forces transferred between the superstructure and substructure.

The specification proposes three methods for linear dynamic analysis of bridges: single-mode, uniform load and multi-mode methods. The single-mode (SM) and uniform load (UL) methods are used for regular bridges and the multi-mode (MM) 
method, which is a response spectrum analysis, is used for irregular bridges. Irregularity in a bridge may be defined as the possibility of coupling among the modes of vibration. This might happen in multi-span bridges with varying support stiffness, curved or skewed bridges. Several failure modes occurred in these types of bridges in the recent earthquakes (see Figure 1). The figure shows typical failure of skew bridges encountered during the Northridge Earthquake of 1994 . The multimode method (MM) is a three dimensional computer analysis, which results the exact periods of vibration. Using the AASHTO's design response spectrum in conjunction with Multi-mode analysis is a common practice for computer analysis of bridges. Recommended linearly elastic procedures are efficient as long as the bridge behaves within elastic limits. If the structure responds beyond the elastic limits, linear analyses may indicate the location of first yielding but cannot predict failure mechanisms and account for redistribution of forces during progressive yielding. This fact makes the elastic procedures insufficient to perform assessment and retrofitting evaluation for bridges in particular and structures in general. Nonlinear (static and dynamic) procedures can overcome this problem and show the performance level of the structures under any loading level.

During an earthquake, it is obvious that bridges are subjected to the multi-directional ground motions. The effect of bilateral excitation can result in the combination of axial force, biaxial bending moment, shear force, and torsion in bridge columns. Special seismic design consideration is required for some specific bridges; such as bridges supported by c-bent columns, curved bridges and skewed bridges because of their irregular structural placement. The seismic response of skew bridge piers needs studying because of various factors that include: (1) there is no clear or specific performance criteria set for the seismic design of skew bridge's piers, (2) skew bridges have irregular structural configuration, and (3) torsion and bilateral actions contribute to the seismic behaviour as shown in Figure 2. This figure schematically explains the causes of torsion and bilateral action existing in a skew bridge's pier. As can be noted the difference in lateral drifts between the pier edges causes the torsional seismic moment. In addition, the skew alignment of the pier with respect to direction of seismic force generates two components of the seismic forces aligned with pier principle directions causing the previously mentioned bilateral action. Further, the rotation of bridge deck about the vertical axis possibly takes place, which induces the torsional moment coupled with other internal force components. The available experimental investigations indicate that the structural capacities of bridge piers significantly decrease when bridge piers are subjected to the combination of bending moment and torsion. Therefore, it is necessary to clarify the effect of seismic torsion in skewed bridge piers.

\section{PERFORMANCE BASED SEISMIC DESIGN}

The focus of seismic design in current bridge codes is one of life safety level without the ability to consider multiple levels of structural performance from various loading conditions. Economic losses due to recent earthquakes are estimated to be many billions of dollars and the numbers will be higher if the indirect losses are included. This fact lets codes committees and decision makers think beyond life safety, which is essential in design, to alleviate economic losses. This trend creates an increased interest in performance-based design for structures. Displacement-based seismic 
engineering or performance-based seismic engineering is relatively a new concept in the field of structural engineering. Displacement based seismic design may be defined as the desire to build a structure with a predictable seismic performance (which is quantified by response displacements) under different seismic hazards [2]. As a result, it can be said that displacement based seismic design is a promise to produce a structure that will perform in a predefined manner (deck displacement in case of bridges). This manner can be specified by a combination of desired performance criteria during earthquakes. The predefined manner is mainly controlled by the safety of bridge users and the repair cost for the allowed damage. One of the main advantages of performance-based design is its ability to show the performance situation of the bridge and its components under different load intensities. The performance situation means that the damage level, if any, can be assessed and a judgment can be made as to which degree this bridge can continue in service.

The performance-based seismic design process evaluates how a bridge is likely to perform considering uncertainties inherent in the quantification of potential hazard and uncertainties in assessment of the actual building response [3]. In performancebased design, identifying and assessing the performance capability of a structure is an integral part of the design process, and guides the many design decisions that have to be taken. It is an iterative process that begins with the selection of performance objectives, followed by the development of a preliminary design, an assessment as to whether or not the design meets the performance objectives, and finally redesign and reassessment, if required, until the desired performance level is achieved. Performance-based design begins with the selection of design criteria stated in the form of one or more performance objectives. Each performance objective is a statement of the acceptable risk of incurring specific levels of damage, and the consequential losses that occur because of this damage, at a specified level of seismic hazard.

While specific performance objectives can vary for each structure, the notion of acceptable performance follows a trend generally corresponding to: (1) little or no damage for small and frequent earthquakes, (2) moderate damage for medium-size, less frequent earthquakes, and (3) significant damage for very large, very rare earthquakes. Once the performance objectives are set, a series of simulations (analyses of building response to loading) are performed to estimate the probable performance of the building under various design scenario events. In the case of extreme loading, as would be imparted by a severe earthquake, simulations may be performed using nonlinear analysis techniques. If the simulated performance meets or exceeds the performance objectives, the design is complete. If not, the design is revised in an iterative process until the performance objectives are met. In some cases, it may not be possible to meet the stated objective at reasonable cost. In which case, some relaxation of the original objectives may be appropriate.

Performance-based design provides a systematic methodology for assessing the performance capability of a bridge. It provides a framework for determining what level of safety and what level of property protection, at what cost, are acceptable based upon the specific needs of a project. It can be used to: (1) design individual bridges with a higher level of confidence, (2) design individual bridges that fall outside of code-prescribed limits with regard to configuration, materials, and systems 
to meet the performance intended by present codes, (3) assess the potential seismic performance of existing bridges, and (4) estimate potential losses in the event of a seismic event. Performance-based seismic design offers society the potential to be both more efficient and effective in the investment of financial resources to avoid future earthquake losses [3].

\section{SIGNIFICANCE OF THE CURRENT WORK}

The current study focuses on the bilateral actions in skew bridges and their effect on the seismic performance to: (1) develop performance-based relationships for skew bridge reinforced concrete piers, and (2) monitor the seismic behaviour of skew bridges piers against as related to the skew angle. In this respect, the relationships between the secant stiffness, length of the formed plastic hinge, and displacement ductility with pier geometry, and vertical reinforcement ratio are obtained. The results of the proposed parametric study can be utilized in addressing the seismic behaviour of skew bridge's piers, curved bridge's piers, and C-bent piers as they all have a common seismic behaviour regarding torsional and bilateral action generated during earthquakes. The aim of this paper is to address the seismic behaviour of the skew bridge's piers based on the concept of displacement based seismic design.

\section{THEORETICAL INVESTIGATION}

A commercial finite element software package, Strand 7 [4], was utilized in this study. The program contains a solver that allows for full nonlinear analysis that predicts the nonlinear analysis. In Strand7, three types of nonlinearities can be included: geometric, material and boundary nonlinearity. The solver uses an algorithm based on modified Newton-Raphson method [5], which facilitates load increments. Strand 7 allowed easy application of nonlinear static pushover analysis adopted in this study. Strand 7 has an extensive element library including one-dimensional elements (beam elements, truss elements, and cable elements), two-dimensional elements (plates, shells, and membranes), and three-dimensional elements (bricks, wedges, pyramids, hexahedral). For the current study, an 8-noded brick element is used for the 3-D modelling of concrete with or without reinforcing bars (rebar). The element is shown in Figure 3. The brick element has the capabilities of cracking in tension, rushing in compression, a representing both confined and unconfined concrete. Each node has three translational degrees of freedom. Three dimensional truss space bar elements, as shown in Figure 3 were used for modelling steel reinforcement including both longitudinal and confinement reinforcement. The truss element is a uniaxial tensioncompression element with three translational degrees of freedoms. Figure 4 shows the finite element meshing, different elements connectivity, restraints, as well as the material assignment for a typical pier model.

\section{Verification Example}

To verify Strand 7 for use in the current study, a theoretical model was created to simulate the experimentally tested half scale specimens in References [6, 7]. These specimens were tested to evaluate the out-of-plane seismic behaviour of bridge piers. Details of reinforcement and concrete dimensions are shown in Figure 5 . The specimens were tested under slow cyclic loads that were perpendicular to the plane 
of the wall with typical time history shown in Figure 6. Materials properties and strengths are assigned to simulate those of the experimental specimens and as listed in Table 1.

Table1: Finite element model material properties

\begin{tabular}{|l|c|}
\hline Material & Strength $(\mathrm{MPa})$ \\
\hline Concrete cylinder compressive strength $\left(f_{c}^{\prime}\right)$ & 29 \\
\hline Confinement Reinforcement yield strength $\left(f_{y}\right)$ & 428 \\
\hline Vertical Reinforcement yield strength $\left(f_{y}\right)$ & 424 \\
\hline
\end{tabular}

Mohr-Coulomb yield criterion, called c- $\varnothing$ model, was adopted as a failure criteria for concrete in the finite element idealization. To account for great difference in the strain capacity between the concrete cover and the core concrete, two different C- $\varnothing$ models were introduced. One with moderate properties that provided about $25 \%$ of the concrete strength and it was assigned to cover concrete. The other providing about $95 \%$ of the concrete compressive strength with tensile strength reaching $10 \%$ of the compressive strength was used for the core concrete. With respect to the confinement reinforcement limiting stresses, the stress was allowed to reach $60 \%$ of the yield stress based on observations during the tests of the wall specimens. On the other hand, for vertical bars, $75 \%$ of steel yield stress was assumed in the analysis to capture the experimental behaviour.

The pier models were analyzed under force controlled pushover analysis with triangular load pattern [8]. The obtained results were compared to those from the experimental work [6] in Table 2. As can be noted from the table, the theoretical model had slightly higher yield and ultimate loads and slightly lower drifts. The difference can be attributed to the fact that in the theoretical model, full bond between concrete and reinforcement was assumed. In the real specimens, slip occurs during loading which increased the drifts by almost $15 \%$. In addition, cyclic load applied experimentally played a role in accelerating the failure. The dynamic nature of the load was not considered in the theoretical investigation. This justified the remaining difference between theoretical and experimental yield and failure loads. Overall, it can be judged that the theoretical model results fairly represent the experimental behaviour regarding the yield displacement and its corresponding load. As such, the utilized modelling technique, along with the finite element program Strand7, can be used for the current parametric study.

Table 2: Comparison between experimental and analytical results

\begin{tabular}{|l|c|c|c|c|c|c|}
\cline { 2 - 3 } \multicolumn{1}{c|}{} & \multicolumn{2}{c|}{ Load (kN) } & \multirow{2}{*}{ Diff. \% } & \multicolumn{2}{c|}{ Displacement $(\mathrm{mm})$} & \multirow{2}{*}{ Diff \% } \\
\cline { 2 - 3 } \multicolumn{1}{c|}{} & TH. & EXP. & & TH. & EXP. & \\
\hline Yield & 109.5 & 79.7 & $27.2 \%$ & 24.0 & 32.6 & $-35.8 \%$ \\
\hline Ultimate & 126.0 & 111.2 & $11.7 \%$ & 100.0 & 137.0 & $-37.0 \%$ \\
\hline
\end{tabular}

\section{Study Parameters}

The proposed parametric study covers the following parameters: (1) skew angle of the bridge pier $(\Phi)$ as shown in Figure 7, (2) pier height to its thickness ratio $(\mathrm{H} / \mathrm{t})$ as 
shown in Figure 8, (3) axial load index as per Figure 8, and (4) longitudinal (vertical) reinforcement ratio $\left(\rho_{v}\right)$. Values of Skew angle $(\Phi)$ applied in the parametric study are $0,15,30,45$, and 60 degrees. Values of $\mathrm{H} / \mathrm{t}$ applied in the parametric study are $4,8,12$, and 16. Axial load index adopted in the parametric study is $5 \%$. Axial load index is defined as

$$
\text { Axial load index }=\frac{P}{A_{g} f_{c}^{\prime}},
$$

where $P$ is the applied axial load, $A_{g}$ is the gross area of pier cross section, and $f_{c}^{\prime}$ is the cylindrical concrete compressive strength. The vertical reinforcement ratios are $1 \%, 2 \%$, and $3 \%$, respectively. The confinement reinforcement ratio was kept constant at $0.2 \%$. Figure 9 shows the typical cross section used in the theoretical model for representing the pier specimens. The diameters of the confining and vertical reinforcement, $\mathrm{C}, \mathrm{T}$, were adjusted to produce the required vertical and horizontal reinforcement ratios.

\section{Bridge Pier Loads}

Figure 10 summarizes the loading strategy for the analytical model to account for the combination of skew angle and axial load. The analysis started with pushover analysis up to failure using triangular load pattern with a value of $F_{m}$ at the top and zero at the bottom. Each pier generated an F- $\Delta$ curve, which played the main role in defining the seismic behaviour of the pier. The F- $\Delta$ curve was idealized using FEMA 273 [3] procedures such that the area under idealized curve as the same as that under the actual curve. This step resulted in determining the yield point of the pier, which was utilized in estimating the displacement ductility $\left(\mu_{\mathrm{d}}\right)$. Further processing of the F- $\Delta$ curve provided the value of secant stiffness $\left(\mathrm{K}_{\mathrm{sec}}\right)$ of the analyzed pier. To identify the plastic hinge zone, the pier model was studied at failure load to record the length of formed plastic hinge $\left(L_{p}\right)$, which is the average of heights, in which the concrete crushed, compression reinforcement buckled, and the tension reinforcement yielded. As shown in the figure, the output of the analysis displacement ductility $\left(\mu_{d}\right)$, length of plastic hinge $\left(L_{p}\right)$, secant stiffness $\left(K_{s e c}\right)$ were used to define the relationships that described the seismic behaviour of the skew bridge pier.

\section{RESULTS AND DISCUSSION}

Results of the parametric study are presented in different sets of graphs in Figure 11 to Figure 16. Figure 11 plots the relation between the displacement ductility and height/thickness ratio for different skew angles and vertical reinforcement ratios. Figure 12 provides the relation between the plastic hinge length and the height to thickness ratio for different skew angles and vertical reinforcement ratio. Figure 13 provides the secant stiffness relation with pier height to thickness ratios. Figure 14 through Figure 16 are similar, however they provide the relation between displacement ductility, plastic hinge length, and the secant stiffness and the vertical reinforcement ratio, respectively. As shown in Figure 11, displacement ductility with values ranging between 2.8 to approximately eight was recorded in the theoretical investigation. Generally, displacement ductility was reduced as the height to thickness ratio increased. Displacement Ductility $(\mu \mathrm{d})$ maximum values are recorded 
for lowest height to thickness ratio $(\mathrm{H} / \mathrm{t}=4)$ and $\Phi=0^{\circ}$ (no skew) for most investigated cases. An exception occurred for the case of vertical reinforcement ratio of $1 \%$ at $\mathrm{H} / \mathrm{t}$ of 12 . The displacement ductility drops considerably when the skew angle increases from $\Phi=0^{\circ}$ to $\Phi=15^{\circ}$. The greatest drop was noticed for ratios of height to thickness ratio of less than eight $(H / t>8)$, i.e., slender piers. For $H / t$ of 4 , displacement ductility experiences lower variations against skew angle. Further, Figure 11 shows the effect of skew angles is more significant on the displacement ductility for piers with low vertical reinforcement ratio $(\rho v=1.00 \%)$ than in piers with higher reinforcement ratios. The effect of increasing the skew angle from $15^{\circ}$ to $60^{\circ}$ has less pronounced reducing effect on the displacement ductility than that noted when moving from no angle of skew to a skew angle of $15^{\circ}$. The analysis of data in Figure 11 showed that two main distinctions appear in the displacement ductility plots of the skew bridge's piers. These occur at $\mathrm{H} / \mathrm{t}=8$ and at skew angle $\Phi=15^{\circ}$. The first differentiates between short and slender piers, while the second differentiates between low and moderate to high skew configuration.

Figure 12 outlines the expected damage for piers represented by the ratio of the length of formed plastic hinge to the pier height in relation to the height to width ratio. For all vertical reinforcement ratios, the relative height of plastic hinge region decreases as the height to thickness ratio increases. This was true for all skew angles equal or above $15^{\circ}$. The variation is higher for short piers $(\mathrm{H} / \mathrm{t}<8)$ than for slender piers $(\mathrm{H} / \mathrm{t}>8)$. For bridges with no skew, the increase of $\mathrm{H} / \mathrm{t}$ resulted in increases in the relative height of the plastic hinge zone. The largest relative height of plastic hinge occurred at $\mathrm{H} / \mathrm{t}=12$. Further increases in $\mathrm{H} / \mathrm{t}$ resulted in reductions in the relative length of the plastic hinge zone. On the other hand, the skew angle effect on the relative height of the plastic hinge region is obvious. For skew angles $>15^{\circ}$, there is a uniform reduction in the expected relative length of the formed plastic hinge with the increase of skew angle. Tracing the variation of the extend of the expected seismic damage, the same distinctions captured in the displacement ductility curves were noticed (at $\mathrm{H} / \mathrm{t}=8$ and $\Phi=15^{\circ}$ ). This emphasized the importance of those values in shaping the seismic performance of the skew bridge's piers.

Regarding secant stiffness, Figure 13 illustrates the trends of skew bridge pier stiffness follows during earthquakes with respect to the different studied parameters. For all vertical reinforcement ratios and for $\mathrm{H} / \mathrm{t}$ values $<8$, there is a gradual decrease in the secant stiffness values when increasing skew angle from $\Phi=0^{\circ}$ to $\Phi=45^{\circ}$, while for skew angles $\Phi \geq 45^{\circ}$ no mentioned change occurs for secant stiffness. Significant loss in secant stiffness occurred for $\mathrm{H} / \mathrm{t}<8$ while for $\mathrm{H} / \mathrm{t} \geq 8$ neither $\mathrm{H} / \mathrm{t}$ nor skew angle variation have considerable effect on secant stiffness of skewed pier. As a conclusion, secant stiffness variation was considerable for height to thickness ratio and skew angles larger than 8 and $15^{\circ}$, respectively. On the other hand, for greater values of $\mathrm{H} / \mathrm{t}$ and $\Phi$, secant stiffness experiences very slight changes.

Figure 14 to Figure 16 describe the relation between the same seismic performance factors $\left(\mu_{d}, L_{p}, K_{s e c}\right)$ with the vertical reinforcement ratios. Figure 14 demonstrates that displacement ductility is inversely proportional to the vertical reinforcement ratio. From the figure, it can noted that the differences in the displacement ductility values get smaller with the increase of skew angle. This becomes more noticeable by the 
increase of $\mathrm{H} / \mathrm{t}$ ratio. Figure 15 displays the effect of the vertical reinforcement ratio on the expected relative length of plastic hinge zone in piers. For skew and nonskew bridges, the vertical reinforcement ratio has very slight effect on the expected length of plastic hinge. Analyzing Figure 16 shows that the secant stiffness is directly proportional to the vertical reinforcement ratio. Proportionality is evident for short piers $(\mathrm{H} / \mathrm{t}<8)$, while for $\mathrm{H} / \mathrm{t} \geq 8$ effect of vertical reinforcement is slight.

\section{CONCLUSIONS}

The current work findings ensure the need to develop a new procedure for the seismic design of skew bridge's pier. The procedure should take into consideration the skew angle, detailing and the extent of well-confined confined zones. The following conclusions were drawn from the results of the theoretical program on skew bridge piers:

1- Displacement ductility for skewed piers is very sensitive to the variation of the skew angle at low skew angles $(\Phi \leq 15)$ especially for low vertical reinforcement ratio.

2- The displacement ductility is reduced as the amount of vertical reinforcement increased if the confining reinforcement ratio is kept constant.

3- Effect of skew angle becomes less significant for $(\Phi>15)$ and for piers of $\mathrm{H} / \mathrm{t}>8$ and having vertical reinforcement ratio greater than $1 \%$ on all ductility parameters.

4- Plastic hinge length decreases as the skew angle increases. Vertical reinforcement ratio does not contribute significantly in extending the length of plastic hinge.

5- Secant stiffness changed significantly with skew angle variation for short piers. Its variation for slender piers is less pronounced.

\section{REFERENCES}

1. American Association of State Highway and Transportation Officials, AASHTO LRFD Bridge Design Specifications, Customary US Units, Fourth Edition, Washington, D.C.: American Association of State Highway and Transportation Officials, 2007.

r. American Society of Civil Engineers, "Prestandard and Commentary for the Seismic Rehabilitation of Buildings", FEMA-356, Federal Emergency Management Agency, Washington, D.C., 2000.

r. Building Seismic Safety Council. "NEHRP Guidelines for the Seismic Rehabilitation of Buildings", FEMA-273, Federal Emergency Management Agency, Washington, D.C., 1997.

£. Strand7 Pty Ltd, Strand7 Release 2.2.3 Finite Element Program, Sydney, Australia, 2003.

๑. K. J. Bathe, Finite Element Procedures, Prentice Hall, New York, USA, 1995. 
7. Abo Shadi, N. A., Saiidi, M. S., and D. H. Sanders, "Out-of-plane Seismic Response of Reinforced Concrete Bridge Pier Walls", ACI Structural Journal, V. 97, No. 6, pp. 803-812, 2000.

V. Abo Shadi, N. A., Saiidi, M.S., and D. H. Sanders, "Performance-Based Design of Confinement Reinforcement in Reinforced Concrete Bridge Pier Walls for Out-ofPlane Seismic Loads", ACI Structural Journal V. 98, No. 1, pp. 3-15, 2001.

^. Chopra, A. K., and R. K. Goel, "A Modal Pushover Analysis Procedure to Estimate Seismic Demands for Buildings: Theory and Preliminary Evaluation", PEER Report 2001/03, Pacific Earthquake Engineering Research Center, College of Engineering, University of California Berkeley, 2001. 

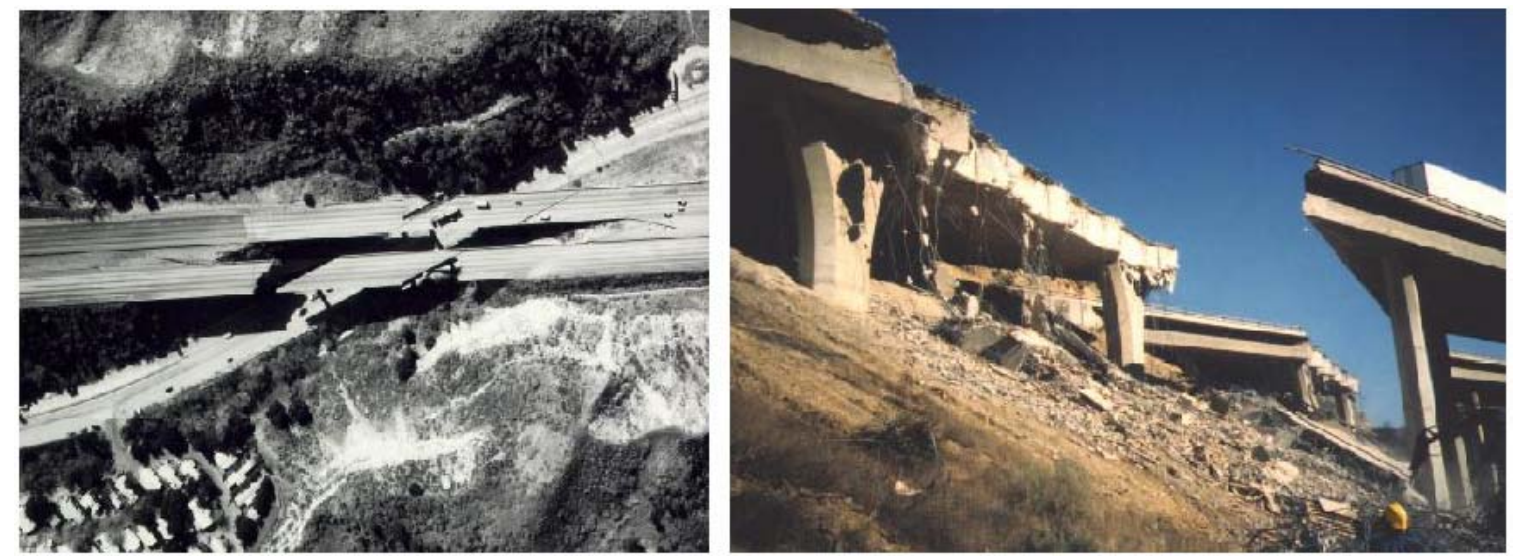

Figure 1. Gavin Canyon under crossing collapse in the 1994 Northridge earthquake

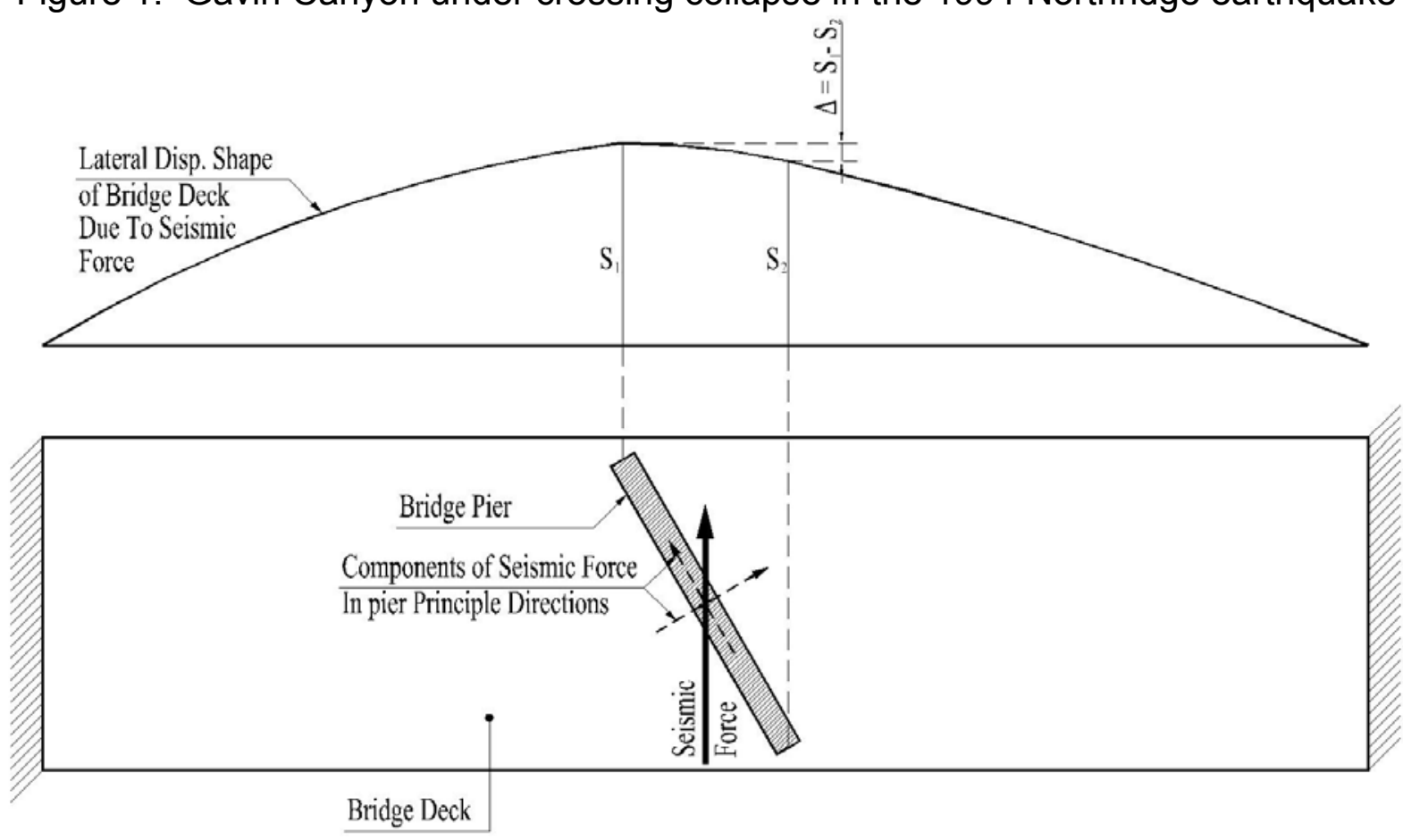

Figure 2. Schematic seismic action on skew bridge piers

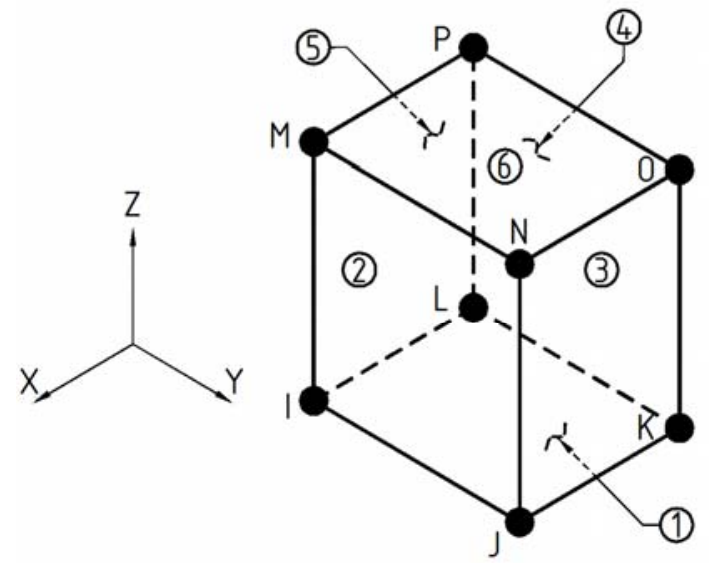

(a) BRICK ELEMENT

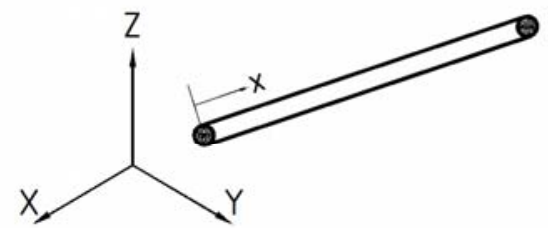

(b) TRUSS SPACE ELEMENT

Figure 3. Brick elements and truss elements 


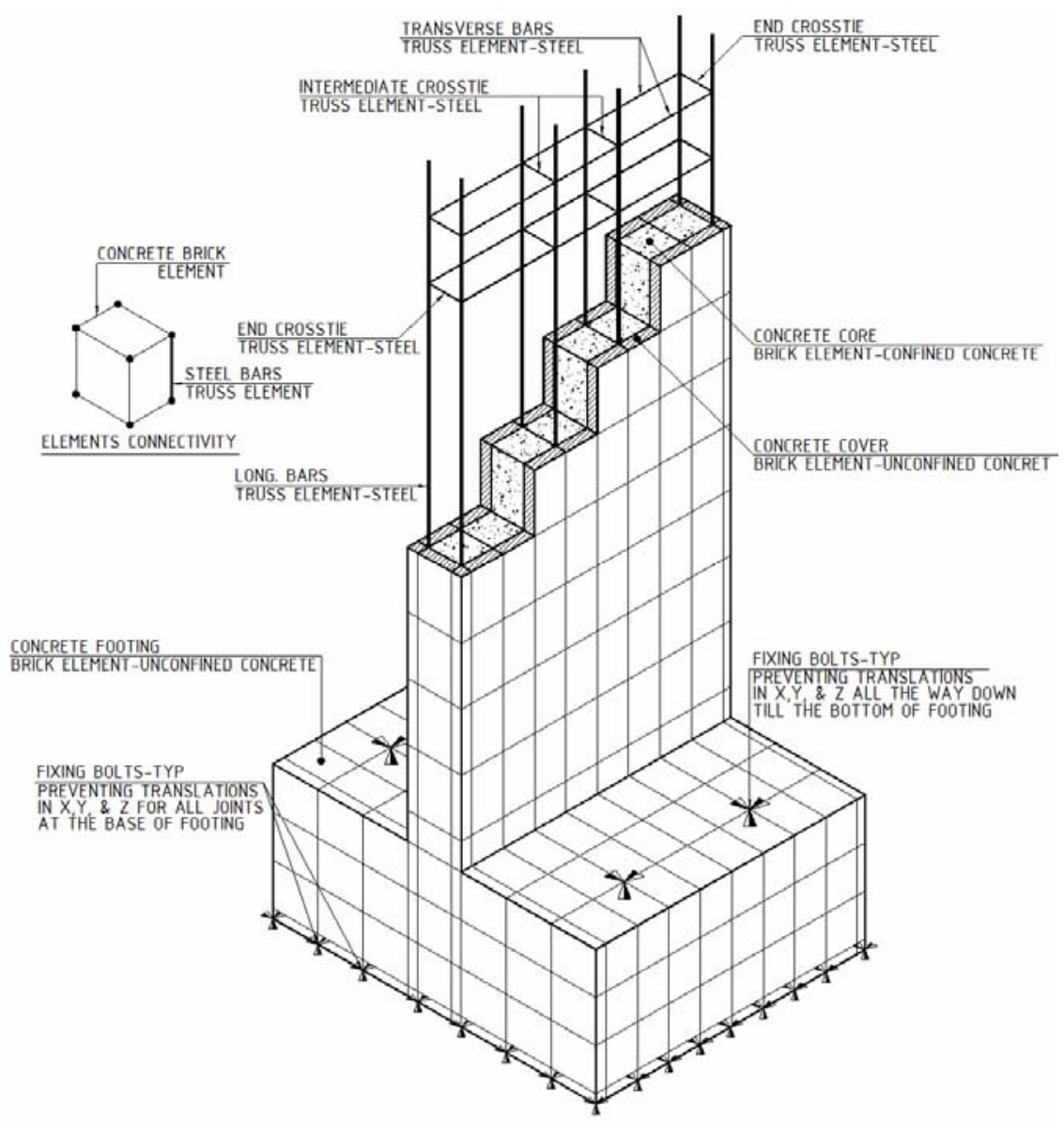

Figure 4. . Presentation for finite element model (materials, elements, and restraints)

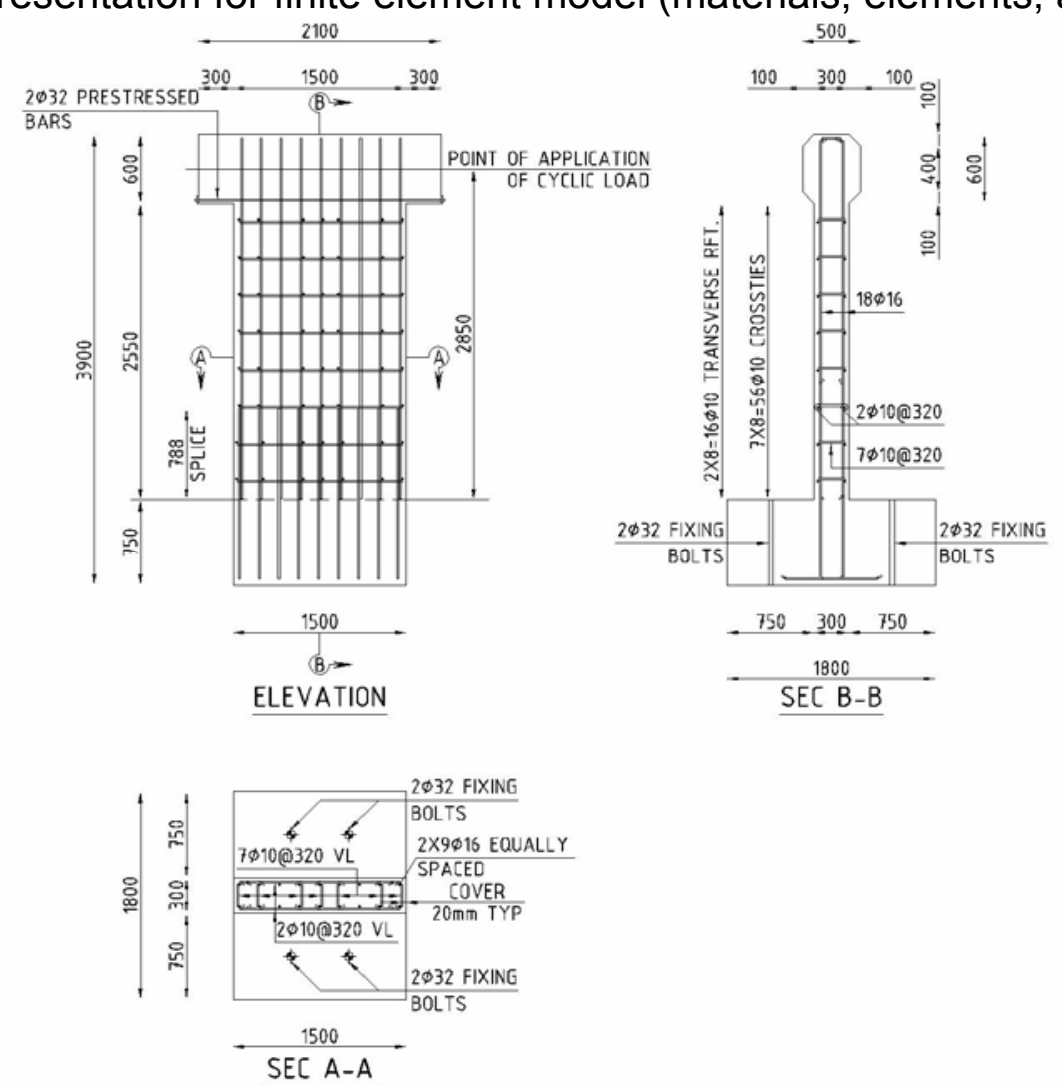

Figure 5. Details of specimen used in the Reference [6] 


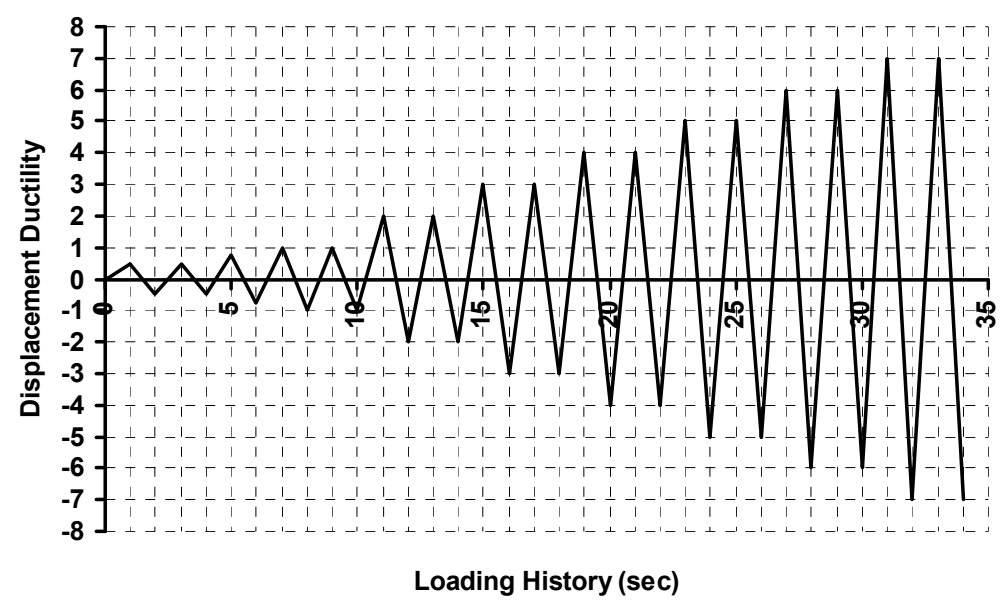

Figure 6. Typical lateral load history applied on the specimen

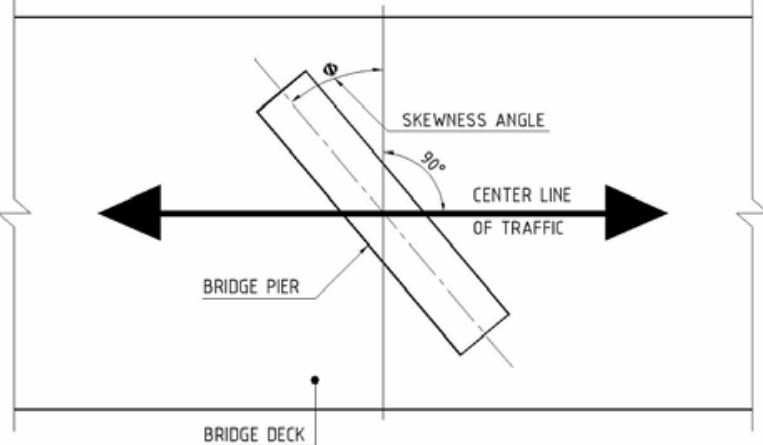

Figure 7. Bridge pier skew angle
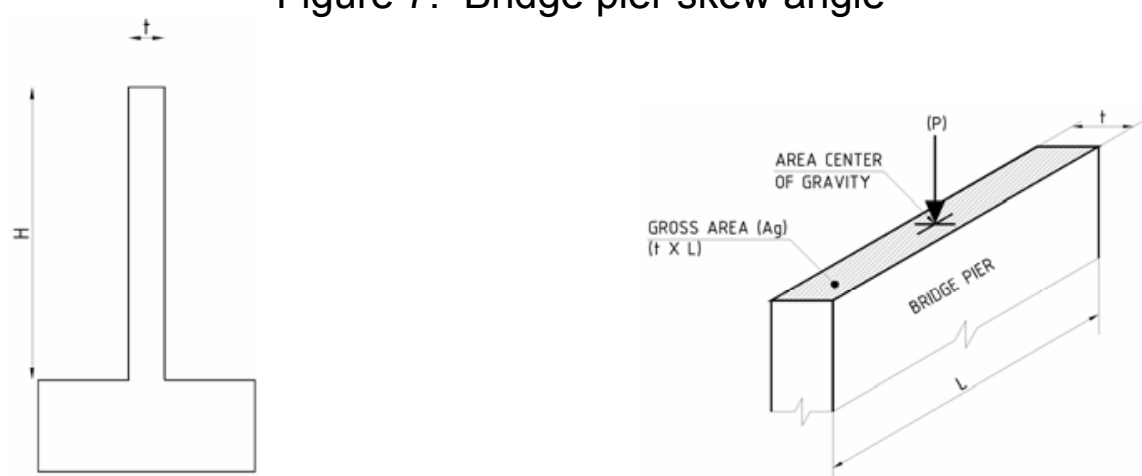

Figure 8. Typical bridge pier elevation and axial load index definition

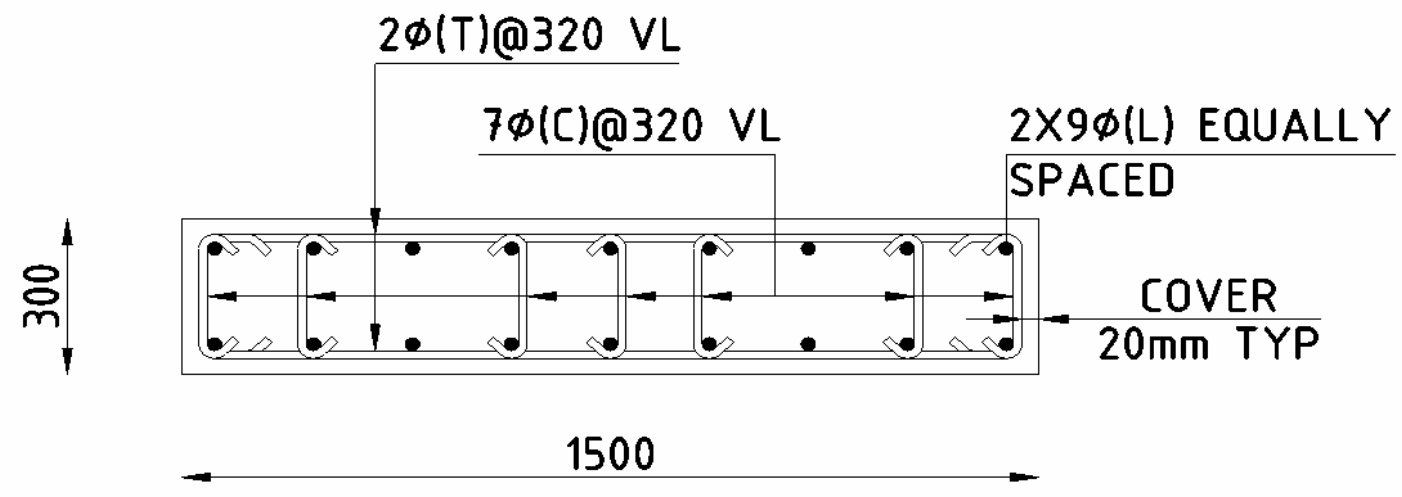

Figure 9. Typical pier cross section of analytical model 


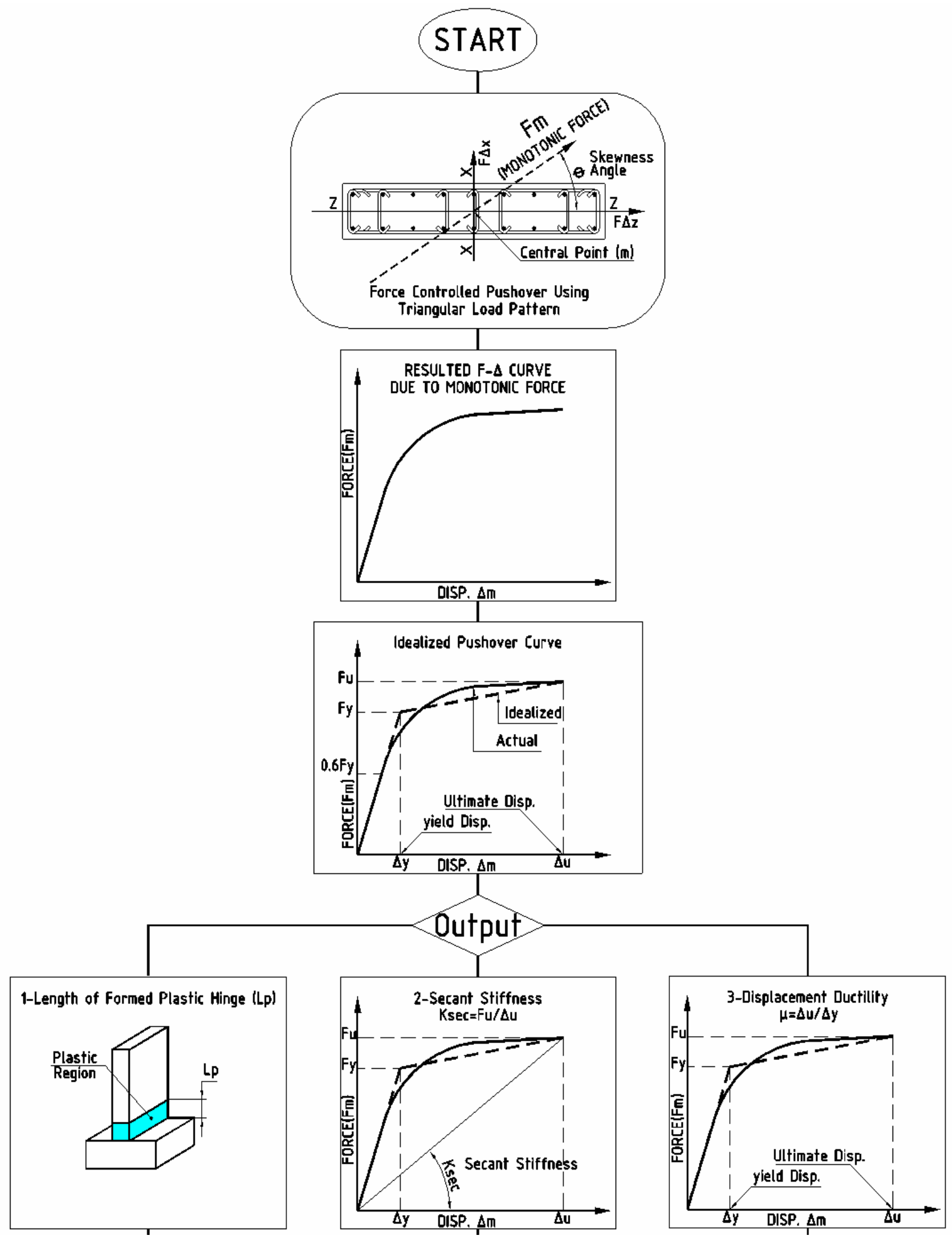

Figure 10. Schematic diagram for loading strategy 

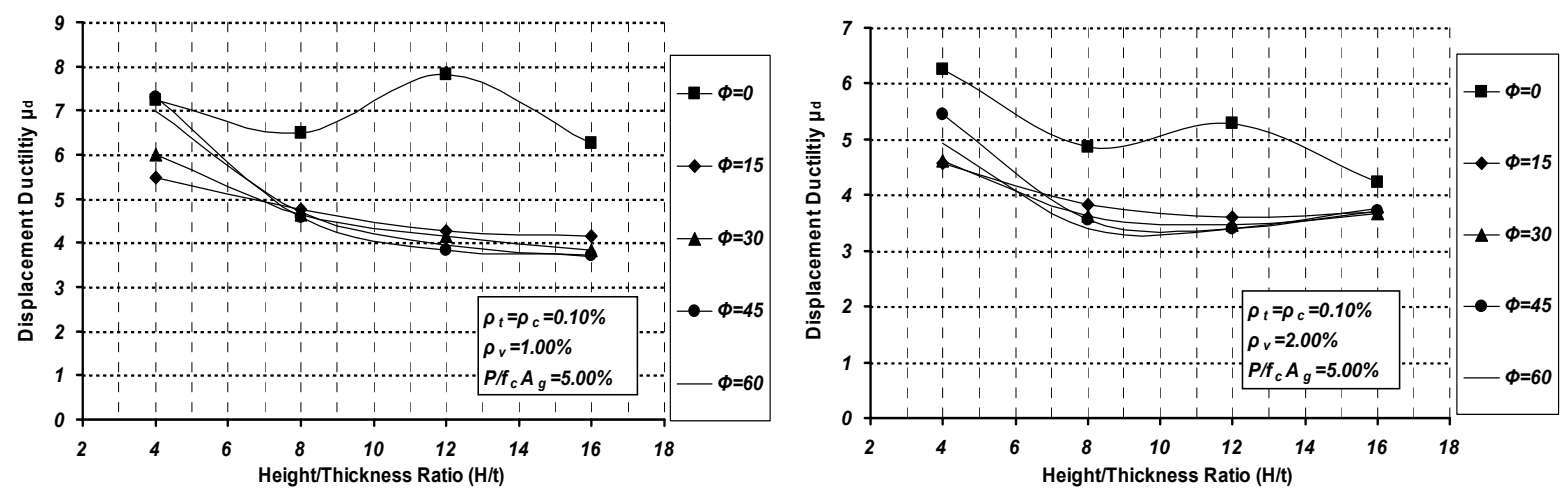

(a) Displacement ductility at $\rho_{v}=1.00 \%$

(b) Displacement ductility at $\rho_{\mathrm{v}}=2.00 \%$

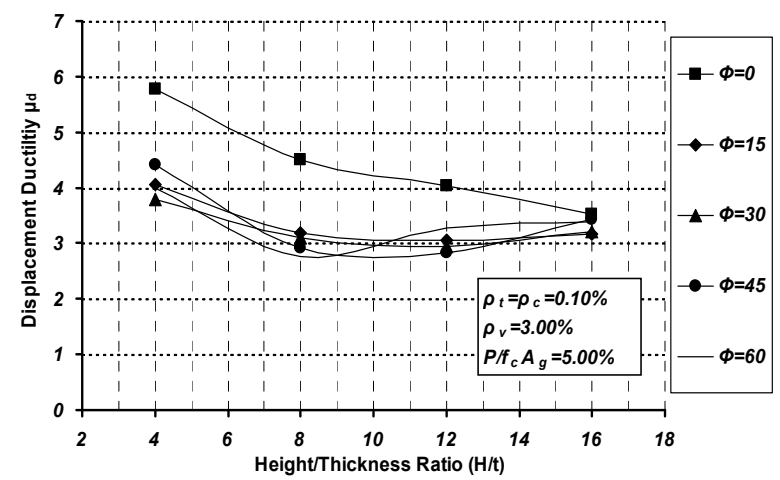

(c) Displacement ductility at $\rho_{v}=3.00 \%$

Figure 11. Displacement ductility relation to height to thickness ratio
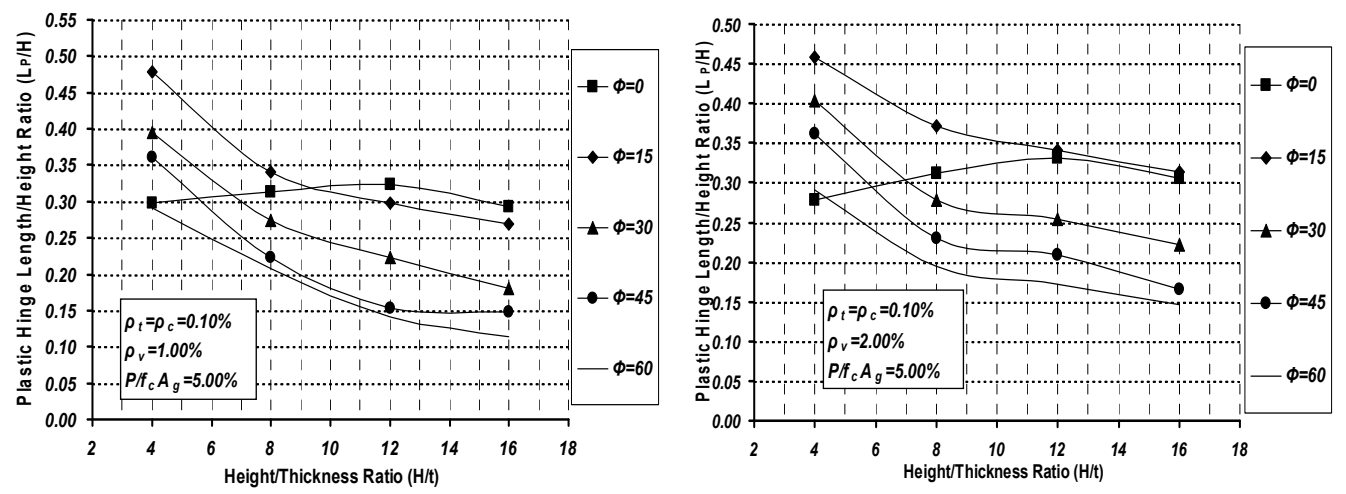

(a) Plastic hinge length at $\rho_{v}=1.00 \%$

(b) Plastic Hinge Length at $\rho_{v}=2.00 \%$

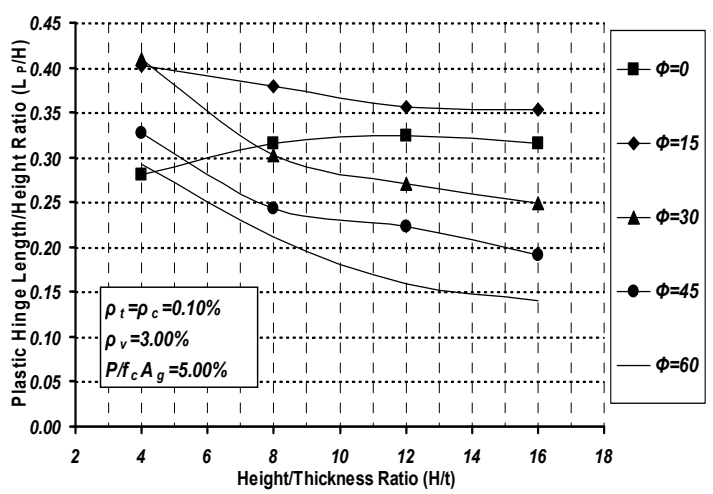

c) Plastic Hinge Length at $\rho_{v}=3.00 \%$

Figure 12. Plastic hinge length relation with height to thickness ratio 


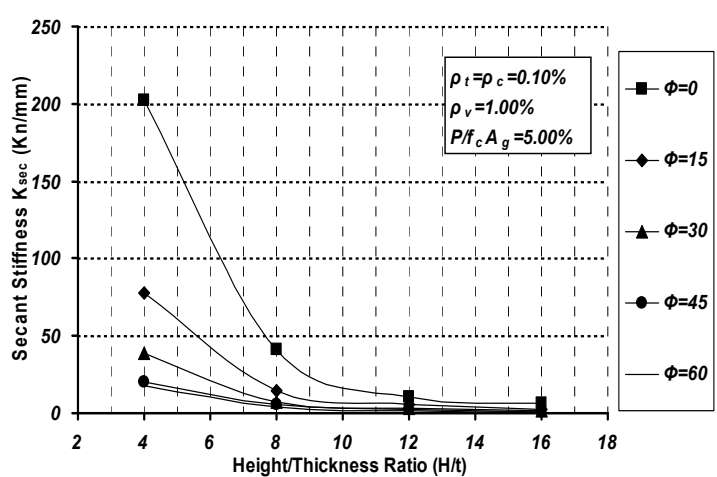

(a) Secant stiffness at $\rho_{v}=1.00 \%$

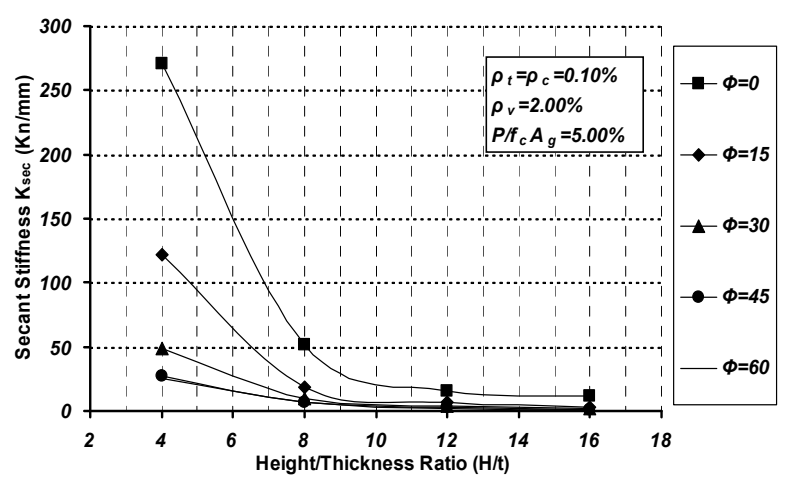

(b) Secant stiffness at $\rho_{v}=2.00 \%$

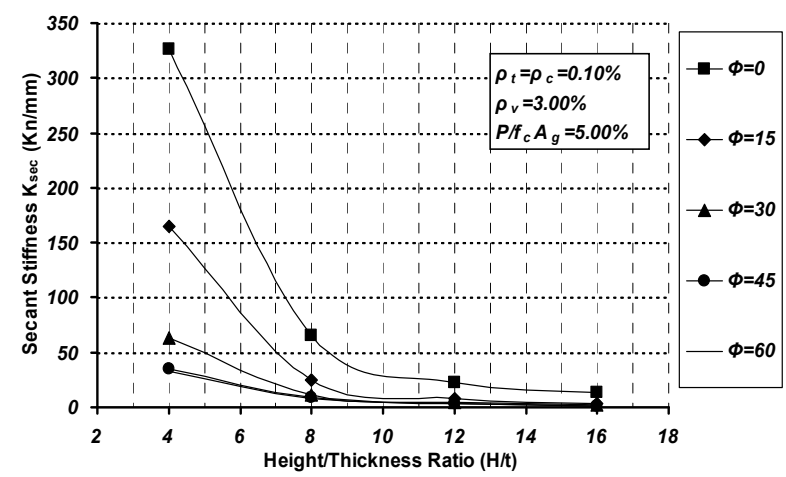

(c) Secant stiffness at $\rho_{\mathrm{v}}=3.00 \%$

Figure 13. Secant stiffness relation with height to thickness ratio

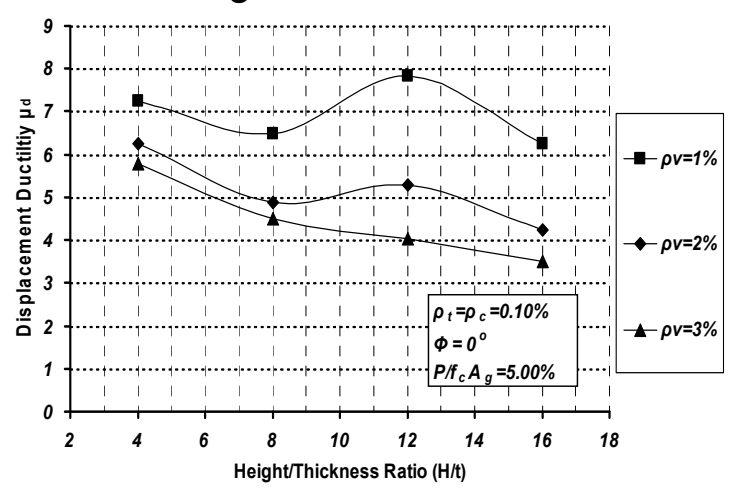

(a) $\mu_{\mathrm{d}}\left(\Phi=0^{\circ}\right)$

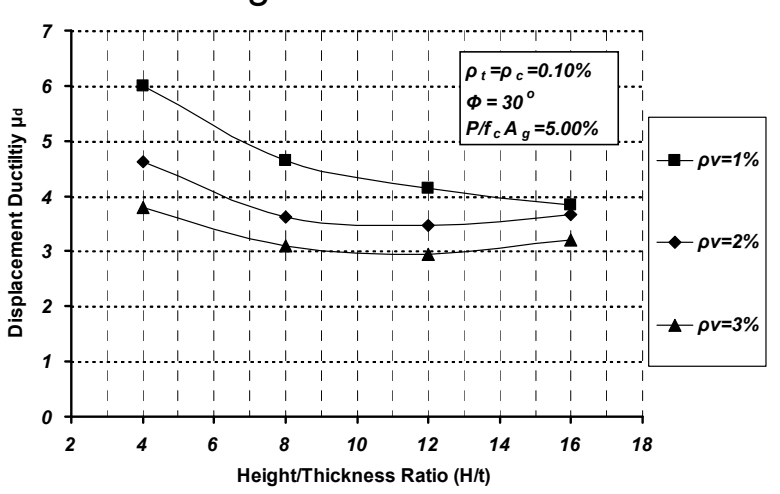

(b) $\mu_{d}\left(\Phi=30^{\circ}\right)$

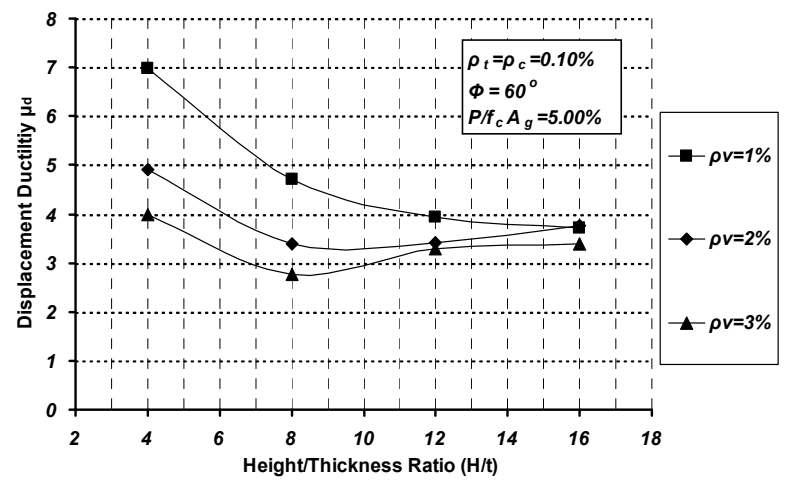

(c) $\mu_{d}\left(\Phi=60^{\circ}\right)$

Figure 14. Relation between vertical reinforcement ratio and displacement ductility 


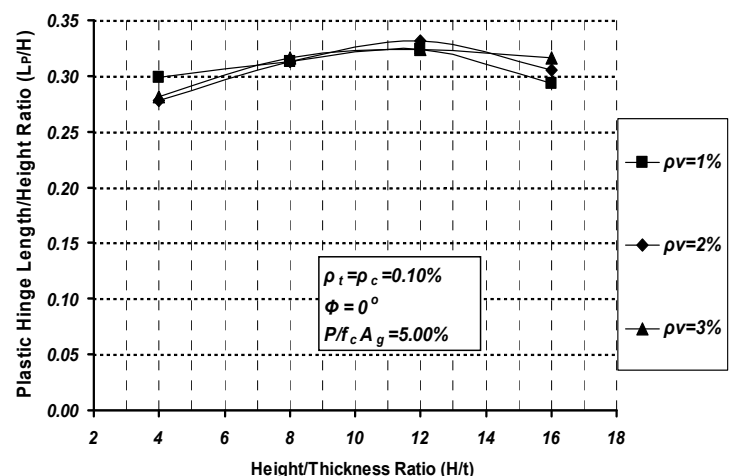

(a) $L_{p} / H\left(\Phi=0^{\circ}\right)$

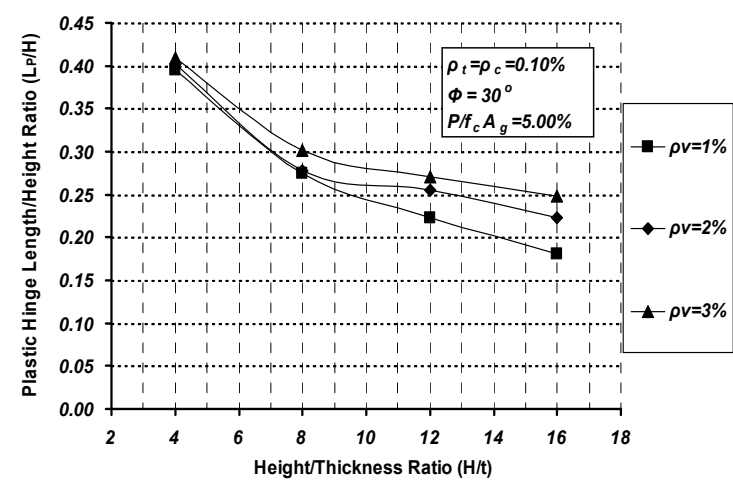

(b) $L_{p} / H\left(\Phi=30^{\circ}\right)$

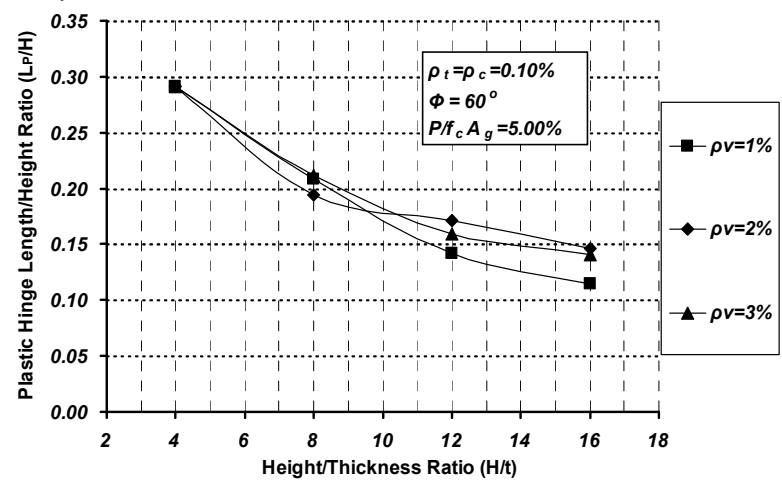

(c) $\mathrm{L}_{\mathrm{p}} / \mathrm{H}\left(\Phi=60^{\circ}\right)$

Figure 15. Relation between vertical reinforcement ratio and plastic hinge length

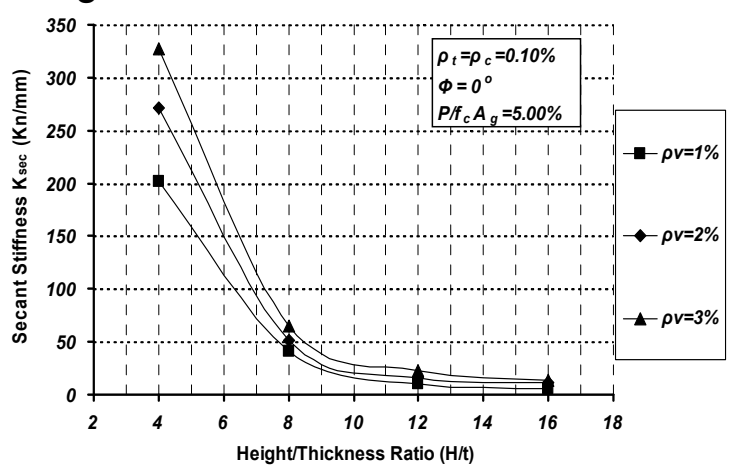

(a) $\mathrm{K}_{\mathrm{sec}}\left(\Phi=0^{\circ}\right)$

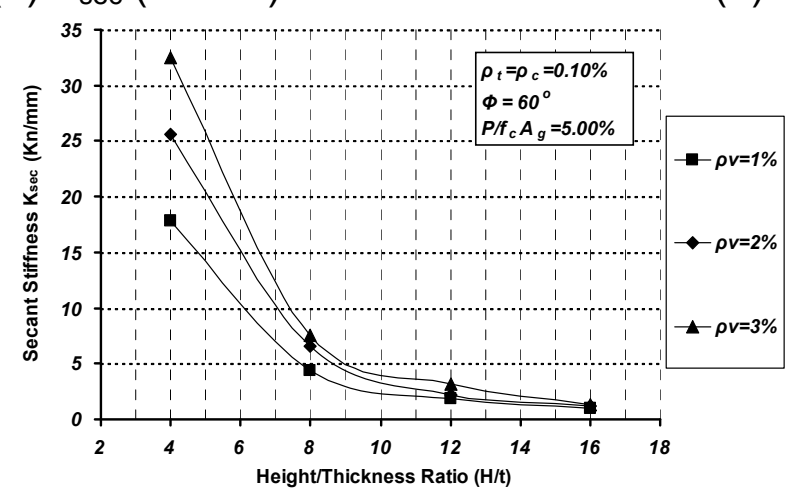

(c) $\mathrm{K}_{\mathrm{sec}}\left(\Phi=60^{\circ}\right)$

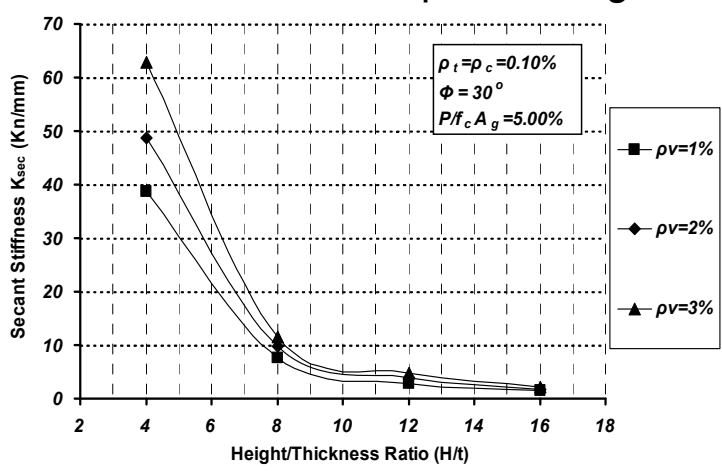

(b) $K_{\text {sec }}\left(\Phi=30^{\circ}\right)$

Figure 16. Relation between vertical reinforcement ratio and the secant stiffness 